\title{
QUALITY MANAGEMENT SYSTEM IN SELECTED ENTERPRISE:CASE STUDY
}

\begin{abstract}
Quality Management System consistent with the PN-EN ISO 9001:2009 standard was developed to ensure meeting customers' requirements and constant improvement in quality of products and services. The system allows for effective and efficient business to maintain market position and adjust to variable conditions in the market. This chapter contains the description of the already implemented quality management system (QMS). The system was presented with the example of the enterprise that manufactures components made of thermoplastics.
\end{abstract}

Keywords: quality management system, ISO standards, quality

\section{Introduction}

Nowadays, market economy and substantial competition forces enterprises to implement various management systems and compete for awards and certification marks. Having the certificate of the quality management system (QMS) in the enterprise is important to many customers. The system helps not only improve the image of the enterprise but it also improves organization and management in terms of quality (KONSTANCIAK M., KONSTANCIAK E., BORKOWSKI S. 2002; KOnSTANCIAK M., STASIAK-BETLEJEWSKA R. 2010). The main assumption of such a quality management system is the need for continuous development and improvement, leading to the increase in efficiency and effectiveness (DZIUbA S.T., PIEKara A., MaŁas W., KoZIOŁ P. 2013; PN-EN ISO 9001:2009).

\footnotetext{
${ }^{1}$ dr inż., Wroclaw University of Economics, Poland, Faculty of Engineering and Economics, Department of Labour and Industrial Relations, email: szymon.dziuba@ue.wroc.pl

${ }^{2}$ dr inż., Czestochowa University of Technology, Faculty of Management, Institute of Production Engineering,email: manuela@gazeta.pl

${ }^{3}$ graduate
} 
The aim of this chapter was to present the existing quality management system. The system was implemented in an enterprise that manufactures components made of thermoplastics.

\section{Characterization of the research object}

The enterprise $\mathrm{X}$ belongs to the sector of small and medium-sized enterprises. It was established in 2003 and now employs around 50 employees. The headquarters of the enterprise are located near Jelenia Góra, Poland. The enterprise is mainly involved in production of components made of thermoplastics using injection moulding machines. As a cooperation manufacturer, the enterprise supplies products for the cosmetic industry, household appliances and automotive sectors. Some $40 \%$ of the enterprise's sales is from exported products.

Implementation of the system and then getting the PN-EN ISO 9001:2009 certificate for manufacturing of products made of plastics using the injection moulding method allowed the enterprise to find new customers, also from the previously unavailable sectors.

\section{Aim of the study}

This study was aimed to analyse the Quality Management System developed based on the requirements of the ISO 9000 standard and adjusted to the needs of the enterprise. The main focus of the analysis was on the areas connected with the process of continuous improvement and correct documentation. The following research methods were used to achieve the study aim:

- Literature review - the use of the related literature allowed to draw adequate conclusions.

- Observation - provided necessary materials concerning the problems analysed in the study. 
- Analysis of documentation, which allowed for collecting detailed information about the QMS.

\section{Evaluation of the quality management system in the enterprise studied}

The Quality Management System in the enterprise X was developed based on the ISO 90012008 standard. The process of certification was carried out in November 2013 by TÜV Süd.

The basis for development and implementation of the Quality Management System in the enterprise was:

1. Ensuring meeting the customers' requirements and expectations.

2. Providing conditions for safe and efficient services through:

- utilization of the potential of knowledge and experience of employees that ensure continuous and resilient operation of the enterprise,

- continuous improvement of the processes, procedures and methodologies in order to provide the services at the highest level possible.

3. Ensuring the effectiveness and stability of processes through application of well-proved and reliable procedures.

4. Creation of conditions for continuous improvement and system development.

The Quality Management System is represented by the groups of processes connected with:

- management,

- ensuring availability and maintaining resources: personnel, knowledge, methodologies, infrastructure and equipment,

- providing services for customers,

- monitoring, control, analysis and improvement.

The basic system document is the Quality Manual, which presents the Quality Management System in a comprehensive manner and determines the basic principles of its operation. The Quality Manual also contains the 
Quality Policy, stipulates the responsibility of managers for the quality management system and describes the conditions of meeting the requirements of the EN ISO 9001-2008 standard.

\subsection{Quality policy}

The Management Board are responsible for the development and approval of Quality Policy which represents the framework for determination of priorities and quality objectives. Quality policy in the enterprise $\mathrm{X}$ is implemented to be followed by all the employees through:

- supplying products with the highest quality to customers to fully meet their requirements and expectations,

- continuous improvement in all the areas of enterprise's activities,

- creation of new solutions adjusted to customers' needs,

- dialogue with customers,

- employing competent people who are aware of their effect on the product at all positions,

- continuous improvement of qualifications through trainings and seminars,

- optimization of the model of enterprise's operation,

- the use of services provided exclusively by reliable suppliers,

- respecting legal regulations.

\subsection{Requirements concerning QMS}

The following operations were performed during development, documenting, implementation and maintaining the QMS in the enterprise $\mathrm{X}$ :

1. Definition of the processes necessary for the quality management system.

2. Definition of the order of processes and their mutual effect. 
3. Definition of the criteria and methods that ensure efficient performance of these processes.

4. Ensuring availability of resources and information to support performance and monitoring of these processes.

5. Definition and implementation of monitoring, measurement and analysis of core processes if applicable.

6. Application of current measures necessary for achievement of the planned results and continuous improvement of these processes.

Characterization and map of certain processes are presented in Figure

1. The managers in the enterprise $X$ defined the criteria and resources necessary for the processes and specified the methods to effectively supervise and improve the processes. 


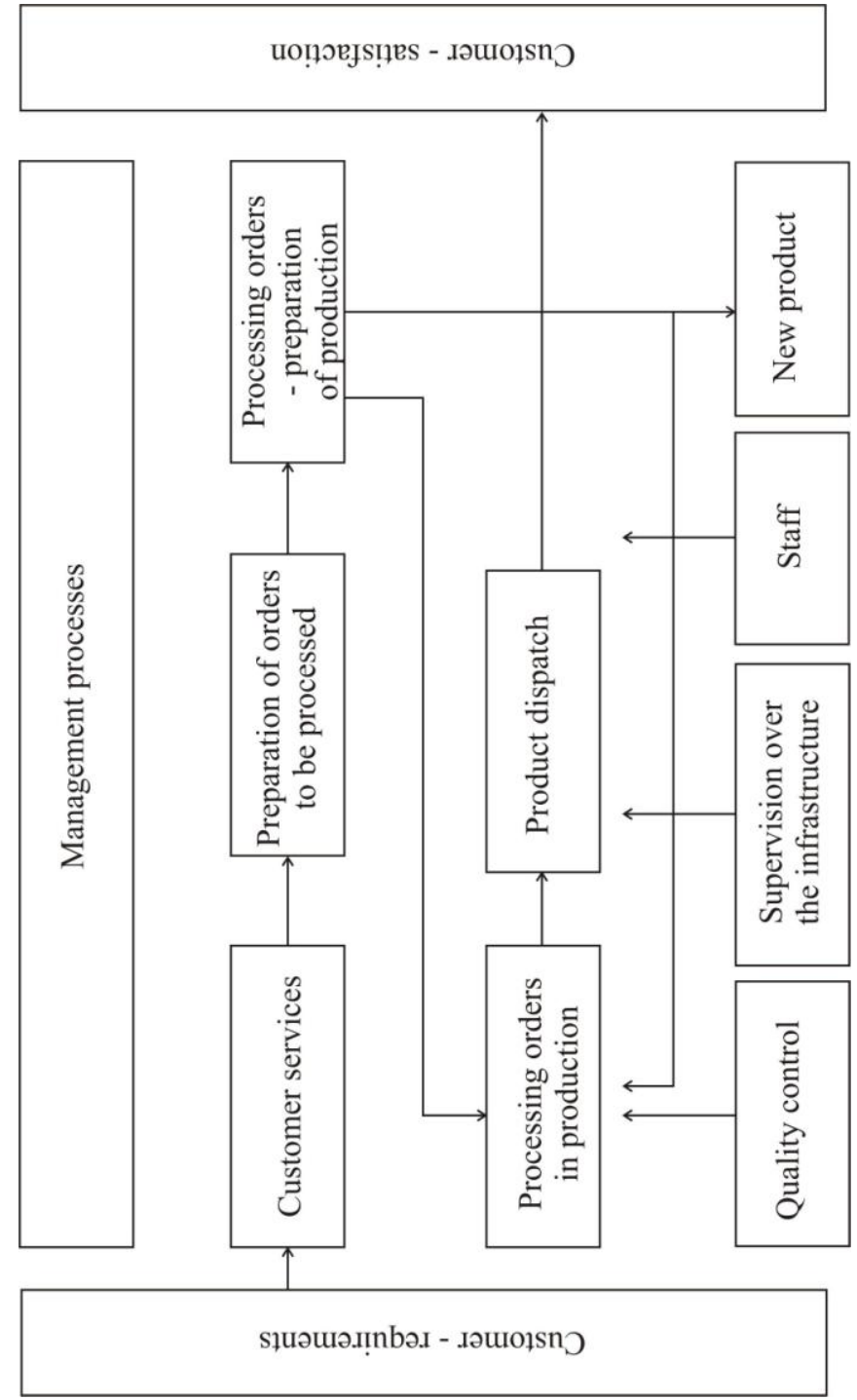

Fig. 1. Process map.

Source: Quality Manual of the research enterprise 
Effectiveness of achievement of quality objectives is evaluated through:

- analysis of the results of work performed by the Management Board,

- internal audits,

- direct supervision of the managers.

For the purposes of the QMS, the Quality Manual, procedures, instructions and forms (for ensuring that the quality provisions are implemented) were developed. Combined with current regulations, standards and rules, they describe individual processes and activities. Supervision over the documents and provisions is properly described in the procedure P-4.2.0 "Supervision of quality documentation, regulations and records".

\subsection{Managers' responsibility}

Managers in the enterprise are committed to preparation, implementation and development of the QMS and continuous improvement of its performance through:

- raising employees' awareness of the importance of meeting customer requirements and relevant regulations,

- development of the policy and quality objectives,

- supervision over the QMS through management reviews,

- motivating employees to increase their commitment and improve quality of tasks performed at individual workplaces,

- ensuring resources to perform quality tasks,

The managers are also involved in activities aimed at meeting customer expectations through:

- ensuring appropriate analyses, requirements and related regulations to meet them at all stages of product,

- development of communication with customers,

- evaluation and improvement of internal executive capabilities,

- organization of customer satisfaction surveys. 
Through direct supervision over the planning processes, the management board take into account all the objectives and tasks connected with meeting the requirements while focusing on the increase in customer satisfaction. Planning concerns:

- relevant production tasks,

- costs and finance,

- sales,

- employment and training,

- supporting the infrastructure.

The Quality Policy stipulates concrete objectives and tasks for individual functions. The effectiveness of achievement of these objectives is evaluated through:

- analysis of the results of work performed by the Management Board,

- internal audits,

- direct supervision of the managers.

People employed at individual positions have specific competencies and responsibilities and cooperate at specific stages of preparation and production to ensure the compliance with requirements for the products. Individual scopes of activities and, individual chapters of the Quality Manual and procedures stipulate competencies and responsibility of persons. The employees in the enterprise were familiarized with the scopes of authorization and responsibility of people that cooperate with them. The necessary principles of internal communication that allow for transfer of information and data necessary for performance of professional duties and cooperation were established in the enterprise $\mathrm{X}$.

The elements of communication include:

- meetings of enterprise's managers,

- oral and written instructions,

- meetings with employees,

The management board appointed the QMS Representative. The representative is authorized and responsible for ensuring that the quality system is implemented, maintained and its efficiency is constantly 
improved. The QMS Representative supervises preparation of initial data for management review. These include:

- audit results,

- information from customers,

- information concerning functioning of processes and product compliance,

- state of correcting and preventive measures,

- results and actions from previous reviews,

- changes and their effect on QMS,

- recommendations concerning system improvement.

Once a year, the management board makes a review of compliance and efficiency of the quality management system. The aim of the management review is to evaluate the system effectiveness and directions for QMS improvement.

The output data of the review include:

- decisions and actions concerning improvement of system effectiveness,

- improvement in quality of services/products with respect to customers' requirements,

- allocation of necessary resources.

The final step is preparation of the review protocol signed by all the participants. All the documentation connected with reviews is stored by the QMS Representative.

\subsection{Resource Management}

The enterprise defines and secures the resources necessary for operation of the quality management system and continuous improvement in the effectiveness in order to meet the requirements and improve customer satisfaction. The resources include:

- qualified employee staff,

- adequate financial resources,

- properly equipped work stations, 
- other necessary resources.

The aim of the process is to ensure competent staff and the infrastructure necessary for achievement of tasks and quality objectives.

\subsection{Processes of product manufacturing}

The process of product manufacturing is composed of several components:

Planning of product manufacturing in terms of production is based on orders from customers and demand for products. Production activities are adequately planned and take into consideration:

- quality goals and requirements concerning products,

- needs in the area of processes and necessary equipment,

- criteria for product acceptance,

- required activities concerning verification, control and examinations,

- relevant quality records over the period of product manufacturing.

Production planning relates to

- ongoing production balancing,

- development of product specifications that determine technology, conditions of manufacturing, method of control and documentation of quality,

- technological equipment,

- material planning,

- choice of working and supervisory staff,

- scope of process supervision.

At the stage of planning and implementation of individual processes, availability of resources and information necessary to support and monitor processes is ensured. The competencies of employees required for individual processes were defined in system documentation.

Communication with customer is aimed at providing customers with information, presentation of products and ensuring that the requirements are transparent and complete and that meeting these requirements is evaluated and confirmed. Information from customers, 
including complaints, are recorded and used to take relevant corrective and preventive measures.

The requirements defined by customers, including special requirements, are analysed in relation to the requirements connected with the intended use and regulations. The decision about acceptance of the order to be processed is preceded by obtaining a positive result of the analysis of requirements and evaluation of feasibility and, if the need arises, solving the problems which were found.

The feedback from customers is recorded and used for improvement and the use of the feedback relates to:

- direct processing of complaints,

- improving customer service,

- enhanced organization and processes,

- evaluation of the quality system.

The purchasing process is aimed at ensuring that the materials purchased and services meet specific requirements and are used for achievement of the tasks. The purchasing process is performed by production manager and chief engineer under direct supervision of the Management Board. The purchasing process is performed and supervised in the manner that ensures the required quality of basic materials used for manufacturing. Therefore, suppliers are assessed and the qualification criteria are specified to choose suppliers and verify them in the future. The activities connected with determination of requirements and specifications, and with preparation and review of orders ensure the purchase of materials with demanded quality.

Verification of deliveries helps detect incompatible materials and eliminate them from further processes or supervise their use. If doubts arise, the extended quality control is performed for deliveries under supervision of responsible employees. Identification of materials from deliveries is based on supplier markings while quality status is ensured by supply control and proper storage. Materials consistent with the requirements are stored in the warehouse or directly transferred for production. Conditions of storage of materials are supervised. 
Manufacturing and supply process is supposed to ensure compliance of manufactured and supplied products with the requirements. Preparation of the manufacturing process consists in careful familiarizing with the order and requirements, development of the manufacturing plan, development of quality control schedule, allocation of competent personnel, ensuring necessary materials for production and organization of the workplace. Manufacturing is performed under supervision of production manager. All the technological operations are performed under following supervised conditions:

- employing and allocation of qualified employees to perform tasks,

- providing employees with access to documentation and requirements concerning products,

- preparation and sharing regulations, specifications and other internal documents that regulate procedures,

- ensuring proper equipment in workplaces, including measurement tools and instruments, and supervision of their reliability,

- measurements and examinations of products,

- activities connected with sending products to customers.

After recording of the compliance with the requirements, finished products are transported to the warehouse or directly to customers.

Processing incompatible products in the manufacturing process and after completion of manufacturing is specified and does not generate the risk of accidental sending an incompatible product to other operations or to customers. The method of supervision over the incompatible products and responsibility for the actions are defined in specific procedures.

\subsection{Measurements and analysis}

The process of measurement and analysis is aimed at ensuring the effectiveness of the QMS through collection and analysis of the relevant data, taking appropriate measures and its continuous improvement.

Monitoring and measurements:

- Customer satisfaction: the source of information for evaluation of satisfaction/dissatisfaction of customer is analysis of the data 
concerning the quality of cooperation with customers and analysis of complaints and comments. The evaluation is performed annually and contains conclusions and recommendations for actions. The results and final conclusions in the written form are presented to the Management Board in order to make direct decisions and include them into the management review.

- Internal audits are the most basic tool for evaluation of the effectiveness of the Quality Policy, quality system effectiveness and meeting the requirements of the standard. The system of audits implemented in the enterprise ensures a complete ongoing supervision over the quality system. Audits are organized by employees with relevant competencies, who are not directly responsible for the areas examined. The internal audits concern all the processes and areas in the enterprise included in QMS according to the schedule. Audit follow-up activities are performed by the appointed people and within specific deadlines. The activities performed are evaluated in terms of their effectiveness and they represent the focus of the analysis and evaluation during management reviews. Responsibility and requirements concerning planning and performing audits, documentation of audit recommendations and maintaining the provisions are specified by the procedure P-8.2.2 "Internal quality audit". A direct supervision over internal audits is performed by the QMS Representative.

- Process monitoring is used for all the processes connected directly with achievement of quality goals. The level of achievement of the set goals during individual processes allows for evaluation of their efficiency and effectiveness. The results of monitoring and analyses represent the basis for improvement of processes in the form of corrective and preventive measures. The responsibilities for monitoring of processes are defined within the matrix of processes.

- Measurements and examination of products are carried out in order to ensure and confirm that the products are consistent with the requirements both in the phase of manufacturing and transfer to 
customers. This relates to all the stages in the manufacturing process i.e. control of quality of deliveries, quality control in the process, final control over the final product.

Control over the quality of supplies, quality control in the manufacturing process and control of the finished product is carried out according to the quality control instruction. Product quality control is recorded and stored. The person responsible for the measurements and examinations of products at all stages of the manufacturing process is Quality Specialist.

Supervision over the incompatible products - with respect to incompatible products, the activities in the enterprise are aimed to reliably identify incompatible products and to prevent them from accidental use for further phases in the production process and, at the stage of finished product, from qualification for delivery to the customer.

The incompatible products are identified by the self-control and control of the quality of supplies, process and finished products. The products considered as incompatible are recorded and protected against their accidental use or sending to customers, are analysed, and the decisions are made to specify the procedure that is safe for the quality. Depending on the actual status of quality of the incompatible products, the following options are taken into consideration:

- the use of the product "as it is" after the relevant approval,

- returning the product to the supplier,

- the use of the product after improving, reworking and additional control,

- the use of the product for other purposes,

- rejecting (grinding) the product.

Immediate actions are taken if an incompatible product is detected after the delivery or after a short period of use. Decisions and actions concerning the incompatible product are documented and represent the quality records. Method of supervision of the incompatible product and responsibility for the actions taken are determined in the procedure $\mathrm{P}$ 8.3.0 "Supervision over the incompatible product". 


\section{Data analysis}

The enterprise $\mathrm{X}$ collects and analyses data that allow for evaluation of the developed and implemented Quality Management System. The sources of the data include:

- product specifications for production containing data about product quality,

- records of complaints of customers,

- records of complaints about materials purchased,

- records concerning incompatible products,

- status of preventive measures.

Analysis of the above data provides information concerning the quality of the production process, customer satisfaction, properties and trends in processes together with opportunities for preventive activities, quality of material deliveries and cooperation with suppliers. Data analysis occurs through e.g. collective comparison of results and development of relevant conclusions referred to specific time periods, ongoing data analysis concerning the areas connected directly with product quality. The analyses of measurement results and examinations and results obtained from monitoring of processes can be used for taking appropriate improvement activities. Data analysis is performed by the Management Board.

\subsection{Improvement: key QMS process in the enterprise $X$}

The enterprise analysed in this study improves QMS effectiveness through implementation of the quality policy, achievement of the quality goals, using the data analyses, corrective actions, preventive measures and management reviews. Improvement includes the principles of organization, measurement, analysis and taking actions connected with improvement of quality with respect to: products manufactured in order to increase customer satisfaction, processes used to improve their effectiveness, organization of management to enhance the effectiveness of the quality management system and to improve economic efficiency. 
The improvement activities are based on two main approaches:

- Facilitation activities, based on the PDCA principle.

- Investment activities, which, after implementation, change organization and the process in a specific area in a stepwise manner.

Improvement as a continuous process is realized in the form of corrective activities where results from measurements show nonconformities. These actions are taken in order to eliminate the causes of nonconformities. In the form of preventive measures, when current results of measurements are correct but an improvement is needed to increase customer satisfaction or the non-conformity was observed for the other similar product.

Corrective and preventive measures are taken with respect to the quality system, process and product. These activities are supervised by the QMS Representative. Analysis of nonconformities and corrective measures are used to improve the system, process and product. The scope of corrective and preventive activities depends on the significance of the problem and the effects that can be caused during cooperation with customers. The detailed principles for preventive and corrective measures and required records are specified in the procedure P-8.5.0 "Corrective and preventive measures".

\section{Conclusions}

Analysis of the Quality Management System verifies its proper operation that yields the effects expected in the enterprises in the form of ensuring the quality of products. It is also important that all the complaints in the enterprise are solved immediately to the benefit of customers. With effectively used methods and tools to support quality management, the enterprise can ensure that a specific defect will not occur in the future.

QMS in the enterprise studied is being improved, which is reflected by the records in the documents through: 
- preventive measures that results from the system review performed by the managers,

- analysis of the data specified in the Quality Manual,

- requests to take corrective and preventive measures,

With the process of continuous improvement, definition and achievement of the quality goals, it was possible to improve the structure of employment which consequently led to the improvement in the production area and reduction in general costs in the enterprise while maintaining the costs of complaints at a steady level through careful preparation of technological documentation, causing a reduction in internal costs.

In conclusion, , the QMS system in the enterprise analysed in this study ensures the continuous improvement and increasing the system effectiveness. Eventually, this leads to the reduction in the costs that result from poor quality while improving position of the enterprise in the market and increasing the customer trust with respect to products offered.

\section{Bibliography}

1. DOKUMENTACJA BADANEJ FIRMY X, 2015.

2. Konstanciak M., Konstanciak E., BorKOWSKI S. 2002. Działanie systemu certyfikacji i akredytacji w Polsce. [w:] IX konferencja Naukowo Techniczna Produkcja i Zarządzanie w Hutnictwie, Wydawnictwo Wydziału Inżynierii Procesowej, Materiałowej i Fizyki Stosowanej Politechniki Częstochowskiej, Częstochowa, s. 309 - 312.

3. Konstanciak M., Stasiak-Betlejewska R. 2010. Wdrożenie systemu jakości ustug w firmie spedycyjnej. Logistyka nr 4, s. s. 82-86.

4. PN-EN ISO 9001:2009P, SYSTEMY ZARZĄDZANIA JAKOŚCIĄ - WYMAGANIA.

5. DziUba S.T., PIEKara A., MaŁas W., KozIOŁ P. 2013. Traditional tools of quality improvement used to improve furniture production process. [w:] Quality Control Meaning in Products and Processes Improvement, chapter 6. Ed. S. Borkowski, P. Sygut. University of Maribor, Faculty of Logistics, Celje 2013. 